\title{
THE OXYGEN CONSUMPTION AND EFFICIENCY OF THE RESPIRATORY MUSCLES IN HEALTH AND EMPHYSEMA *
}

\author{
By REUBEN M. CHERNIACK † \\ (From The Winnipeg General Hospital and the Departments of Medicine and Physiology and \\ Medical Research, University of Manitoba, Winnipeg, Canada)
}

(Submitted for publication August 4, 1958; accepted October 23, 1958)

The work of moving the lung, chest wall, diaphragm and abdominal contents during spontaneous respiration is performed by the muscles of respiration. In order to obtain a better understanding of the disability present in pulmonary disease it would be advantageous to have, in normal and diseased states, a measure of the total work being done, the energy cost of performing this work and the efficiency of the muscles of respiration.

There are few measurements of total mechanical work and efficiency of the respiratory muscles in the literature (1). A simple method for the determination of the oxygen consumption and efficiency of the respiratory muscles, as well as an indirect measurement of the total mechanical work, has recently been described (2). Reproducible results were obtained in both a normal and an emphysematous subject intensively studied.

The purpose of this paper is to report further data on the oxygen cost, efficiency and the total mechanical work of the respiratory process in a series of normal and emphysematous subjects.

\section{METHODS}

Subjects. Table I lists the physical characteristics of the 16 normal and 22 emphysematous subjects studied. The normal subjects had no clinical or radiological evidence of cardio-respiratory disease. The diagnosis of pulmonary emphysema was based on the clinical history and examination, and on the radiological and spirographic evidence. Vital capacities and maximum breathing capacities were measured on a Collins respirometer with valves and carbon dioxide absorber removed. The maximum of at least four determinations was chosen. All patients with emphysema showed marked obstruction to expiratory outflow and reduction of the maximum breathing capacity.

Oxygen consumption of the respiratory muscles. The oxygen consumption was determined at rest and at sev-

* Supported by a grant from the National Research Council, Canada.

+ Markle Scholar in Medical Science. eral levels of increased ventilation by a modification of a method previously described (2). The apparatus employed is illustrated in Figure 1. The subject breathed into and out of a $9 \mathrm{~L}$. Collins respirometer with carbon dioxide absorber incorporated. A cam on the pulley of the spirometer activated a micro-switch which in turn opened and closed a solenoid valve through which oxygen could be delivered from a second spirometer. The micro-switch was activated towards end-inspiration so that a nonsloping record of tidal volumes and the integrated minute ventilation were obtained on the first spirometer, while the oxygen being consumed was recorded on the second spirometer.

All subjects were studied in the sitting position, having fasted for at least nine hours and having rested in a comfortable chair for one hour prior to the study. All breathed 100 per cent oxygen from a meteorological balloon for 10 minutes and into and out of the spirometer circuit for five to seven minutes before any measurements were taken. This was done because it was found impossible to obtain reproducible measurements within a shorter time. Seven to 10 minute measurements of oxygen consumption and ventilation were made at rest and during increased ventilation. Oxygen consumption was expressed in milliliters per minute S.T.P.D. and ventilation in liters per minute B.T.P.S.

At least two levels of increased ventilation were achieved by the interposition of dead spaces consisting of thickwalled rubber tubing $(2.5 \mathrm{~cm}$. internal diameter $)$ between

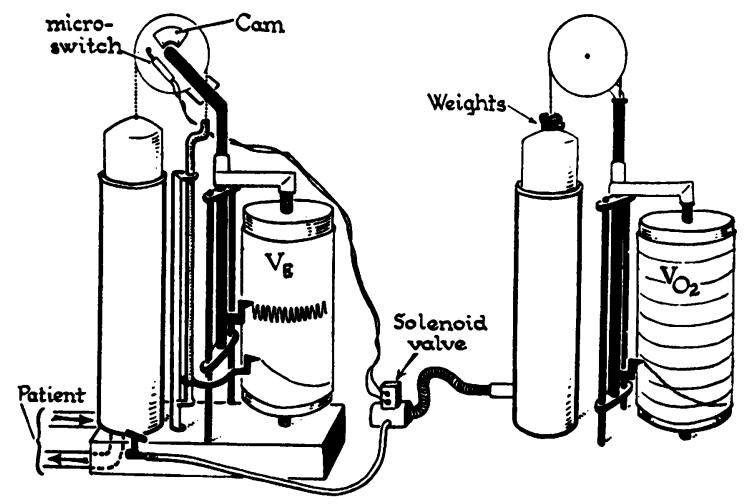

Fig. 1. The Apparatus Employed to Measure Minute Ventilation and Oxygen Consumption in Order to Calculate the Oxygen Consumption and EFficiency of the Respiratory Muscles 
OXYGEN COST AND EFFICIENCY IN HEALTH AND EMPHYSEMA

TABLE I

Physical characteristics and oxygen cost of increased ventilation in normal and emphysematous subjects

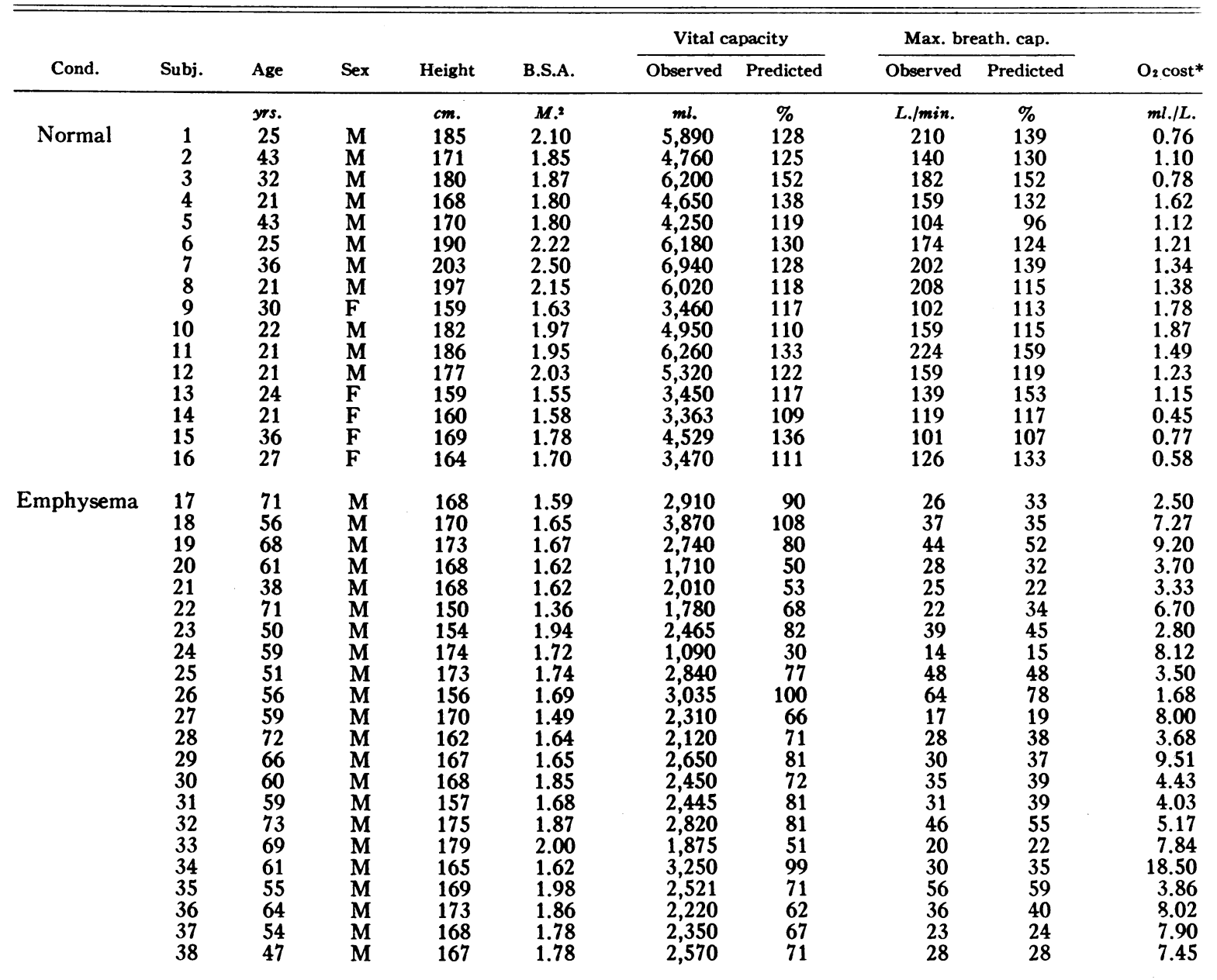

* Oxygen cost of an increase in ventilation of 6 to $10 \mathrm{~L}$. per minute from resting.

the subject and the spirometer, the smaller of the dead spaces producing an increase in ventilation of 6 to $10 \mathrm{~L}$. per minute, and the larger from 12 to $25 \mathrm{~L}$. per minute. The resistance of the whole dead space-spirometer system was less than $1 \mathrm{~cm} . \mathrm{H}_{2} \mathrm{O}$ per $\mathrm{L}$. per second at a flow rate of 1.5 L. per second.

Subjects were allowed to increase their ventilation spontaneously with no control of rate or depth while breathing through a dead space. The sequence in which the various increased levels of ventilation were studied was altered at random. Observations at rest with no added dead space were made at the beginning and end of each series of measurements. Fifteen minutes of rest was allowed between observations, during which time room air was breathed.

For each subject the difference in oxygen consumption at the resting ventilation and at a ventilation 6 to $10 \mathrm{~L}$. above the resting ventilation was divided by the differ- ence in ventilations and expressed as the oxygen cost of increased ventilation in milliliters per liter of ventilation.

Efficiency of the respiratory muscles. The efficiency of the respiratory muscles was determined in nine normal and seven emphysematous subjects by measuring the extra oxygen consumption associated with the performance of a known added respiratory work load, using the respirometer as described above. Work was added by having the subject inspire through metal tubing $(2.5 \mathrm{~cm}$. internal diameter) projecting down under a water seal (2). This produced a constant additional alveolar spirometer pressure difference throughout inspiration, relatively independent of the rate of air flow, and left expiration unimpeded. The time taken for this procedure was identical to that for measuring the oxygen consumption of the respiratory muscles. The added work was calculated by multiplying the minute ventilation 
TABLE II

Oxygen cost and efficiency of the respiratory muscles, determined by the open-circuit and closed-circuit techniques

\begin{tabular}{|c|c|c|c|c|c|c|c|c|}
\hline \multirow[b]{2}{*}{$\begin{array}{c}\text { Test } \\
\text { condition }\end{array}$} & \multicolumn{4}{|c|}{ Subject No. 2} & \multicolumn{4}{|c|}{ Subject No. 3} \\
\hline & $\begin{array}{c}\text { Respiratory } \\
\text { quotient }\end{array}$ & $\begin{array}{c}\text { Added } \\
\text { work }\end{array}$ & $\mathrm{O}_{2}$ cost & Effic. & $\begin{array}{c}\text { Respiratory } \\
\text { quotient }\end{array}$ & $\begin{array}{c}\text { Added } \\
\text { work }\end{array}$ & $\mathrm{O}_{2}$ cost & Effic. \\
\hline \multirow[t]{3}{*}{ Open-circuit } & \multirow{3}{*}{$\begin{array}{l}0.87 \\
0.85 \\
0.76 \\
0.82 \\
0.71\end{array}$} & Kg. M. & $\begin{array}{c}m l . / L . \\
1.35\end{array}$ & $\%$ & \multirow{3}{*}{$\begin{array}{l}0.80 \\
0.76 \\
0.95 \\
1.01\end{array}$} & \multirow{3}{*}{$\begin{array}{c}\text { Kg. } M . \\
4.40 \\
4.27\end{array}$} & $\begin{array}{c}m l . / L . \\
1.12\end{array}$ & \multirow{3}{*}{$\begin{array}{c}\% \\
7.00 \\
7.56\end{array}$} \\
\hline & & 5.48 & & 8.50 & & & 0.96 & \\
\hline & & 5.51 & 0.84 & 7.72 & & & & \\
\hline \multirow[t]{3}{*}{ Closed-circuit } & & & 1.20 & & & \multirow[b]{2}{*}{5.98} & 0.75 & \multirow{3}{*}{$\begin{array}{l}7.12 \\
8.08\end{array}$} \\
\hline & & 4.78 & 1.01 & 7.65 & & & 0.86 & \\
\hline & & 5.36 & 1.12 & 7.25 & & 4.08 & 0.92 & \\
\hline
\end{tabular}

in liters by the added pressure in centimeters $\mathrm{H}_{2} \mathrm{O}$ by $10^{-3}$ and was expressed in kilogram-meters per minute. The extra oxygen consumption associated with the added work load was converted to its energy equivalent assuming a respiratory quotient of 0.82 and expressed in kilogram-meters per minute. The added mechanical work, divided by the energy equivalent of the extra oxygen consumption, yielded the efficiency of the respiratory muscles for handling work loads.

In four normal subjects and three patients with emphysema the efficiency was determined while breathing with three to four levels of added work. The normals were studied with added work loads of from 2.42 to $6.56 \mathrm{Kg}$. M. per minute, while the patients were studied with added work loads of from 0.54 to $2.34 \mathrm{Kg}$. M. per minute. The range of values obtained for per cent efficiency in any one subject was no greater than one. The mean of the determinations in each subject was used in this report.

In order to test the validity of the "closed-circuit" method, the oxygen consumption and efficiency of the respiratory muscles were determined with an "open-circuit" technique in two subjects (Nos. 2 and 3 ). Oxygen consumption was measured at rest and while breathing 5.73 per cent $\mathrm{CO}_{2}$ in air with and without an added inspiratory resistance as outlined above. Expired air was collected in a $300 \mathrm{~L}$. Tissot spirometer and analyzed with a Scholander micro-gas analyzer. Table II compares the oxygen cost and efficiency of the respiratory muscles determined by the "open-circuit" and "closed-circuit" techniques in the two subjects. It can be seen that the values obtained by the two techniques compared favorably.

Total mechanical work of breathing. Knowledge of the energy equivalent of the oxygen cost of breathing and of the efficiency allows calculation of the total mechanical work of breathing at any level of ventilation. The oxygen cost of breathing and efficiency for handling the added work loads can be determined as described above. Our data and that reported previously (2) indicate that the efficiency of the respiratory muscles for handling added work remains essentially unchanged over a large range of added work loads, suggesting that the value for efficiency measured under such conditions may be applied to situations where there is no added work load. Therefore, knowledge of the efficiency and the oxygen cost of breathing at the resting ventilation allows calculation of the total mechanical work of breathing at rest.

In this report the total mechanical work of breathing per liter of ventilation at rest was calculated from the product of the efficiency and the energy equivalent of the oxygen cost of breathing per liter of ventilation at rest and expressed in kilogram-meters per liter of ventilation. This value, multiplied by the resting minute ventilation in liters, yielded the total mechanical work of breathing per minute at rest.

\section{RESULTS}

The oxygen cost of increased ventilation in the normal and emphysematous subjects is shown in Table I. It can be seen that the oxygen consump-

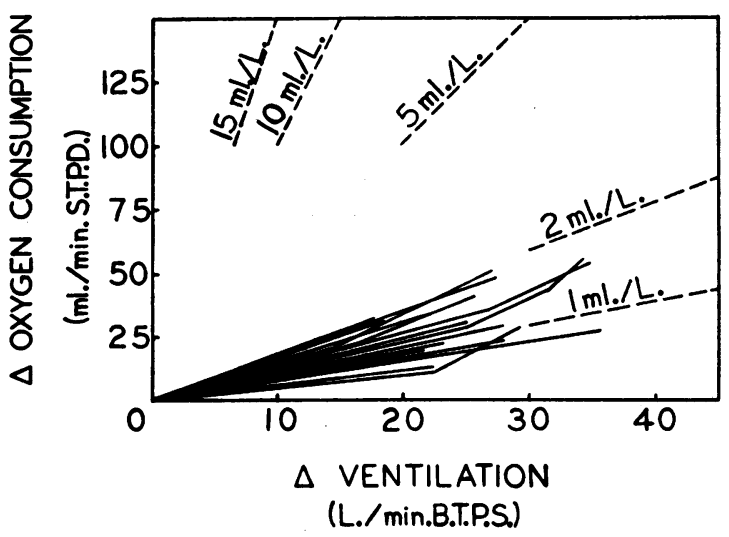

Fig. 2. The Change in Oxygen Consumption Associated with Change in Minute Ventilation in 16 Normal Subjects

Also shown are isopleths representing the oxygen cost of breathing per liter of ventilation. 


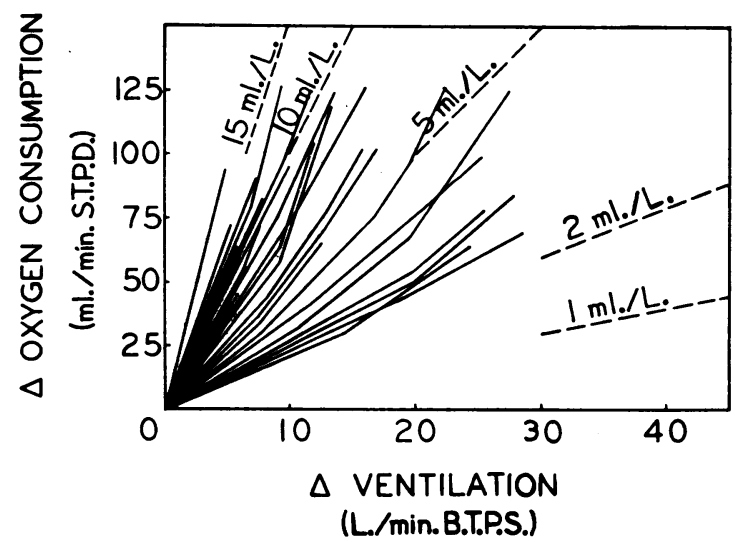

Fig. 3. The Change in Oxygen Consumption Associated with Change in Minute Ventilation in 22 Patients with Emphysema

Also shown are isopleths representing the oxygen cost of breathing per liter of ventilation.

tion of the respiratory muscles per liter of ventilation was considerably higher in the patients with emphysema than in the normal subjects. The cost ranged between 0.45 to $1.87 \mathrm{ml}$. per $\mathrm{L}$. of ventilation (mean 1.16) in the normal subjects, while it ranged between 1.68 and $18.50 \mathrm{ml}$. per L. of ventilation (mean 5.96) in the emphysematous subjects.

In Figures 2 and 3 the increments in oxygen consumption associated with changes in ventilation in the normal subjects and patients with emphysema are shown. It can be seen that in the normal subjects the oxygen cost of an increase in ventilation of $30 \mathrm{~L}$. per minute above the resting ventilation was less than $2 \mathrm{ml}$. per L. On the other hand, in the subjects with emphysema the oxygen cost

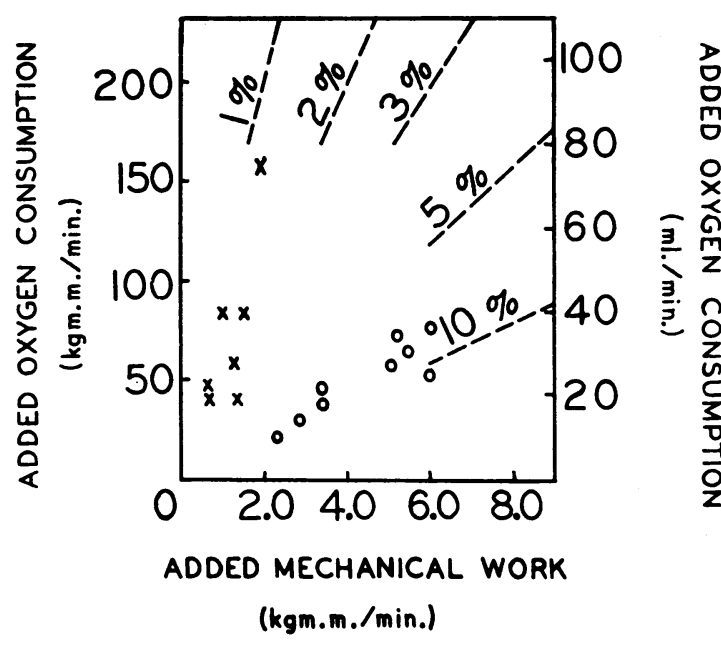

Fig. 4. The Extra Oxygen Consumption Required to Handle Added Respiratory Work Loads in Nine Normal and Seven Emphysematous Subjects

Also shown are isopleths representing the efficiency of the respiratory muscles for handling added work loads. $O$ represents normal subjects; $X$ represents emphysematous subjects.

was high for even slight increases in ventilation and rose still further when ventilation was increased.

The extra oxygen consumption associated with added work loads in nine normal subjects and seven patients with emphysema is shown in Figure 4 . It can be seen that the extra oxygen consumption per unit added work load was greater in the patients with emphysema than in the normals.

In Table III the calculated efficiencies of the respiratory muscles of the nine normal and seven

TABLE III

Total mechanical work and efficiency of the respiratory muscles in normal and emphysematous subjects

\begin{tabular}{|c|c|c|c|c|c|c|c|}
\hline \multicolumn{4}{|c|}{ Normal } & \multicolumn{4}{|c|}{ Emphysematous } \\
\hline Subj. & Efficiency & $\begin{array}{c}\text { Total mech } \\
\text { at }\end{array}$ & $\begin{array}{l}\text { anical work } \\
\text { rest }\end{array}$ & Subj. & Efficiency & $\begin{array}{c}\text { Total mech } \\
\text { at }\end{array}$ & $\begin{array}{l}\text { anical work } \\
\text { rest }\end{array}$ \\
\hline $\begin{array}{l}1 \\
2 \\
3 \\
4 \\
5 \\
6 \\
7 \\
8 \\
9\end{array}$ & $\begin{array}{r}\% \\
10.80 \\
7.45 \\
7.60 \\
8.20 \\
11.10 \\
8.04 \\
7.20 \\
7.43 \\
9.35\end{array}$ & $\begin{array}{c}\text { Kg. } M . / L . \\
0.173 \\
0.172 \\
0.123 \\
0.280 \\
0.326 \\
0.204 \\
0.203 \\
0.215 \\
0.349\end{array}$ & $\begin{array}{c}\text { Kg. M./min. } \\
1.52 \\
1.38 \\
0.82 \\
2.69 \\
3.00 \\
2.74 \\
1.83 \\
1.89 \\
2.27\end{array}$ & $\begin{array}{l}17 \\
18 \\
19 \\
20 \\
21 \\
22 \\
23\end{array}$ & $\begin{array}{c}\% \\
2.74 \\
1.45 \\
2.30 \\
2.04 \\
1.24 \\
1.47 \\
1.60\end{array}$ & $\begin{array}{c}\text { Kg. M./L. } \\
0.141 \\
0.203 \\
0.159 \\
0.120 \\
0.188 \\
0.284 \\
0.123\end{array}$ & $\begin{array}{c}\text { Kg.M./min. } \\
1.39 \\
1.77 \\
1.39 \\
0.83 \\
1.20 \\
2.68 \\
1.22\end{array}$ \\
\hline Mean & 8.58 & 0.227 & 2.02 & & 1.83 & 0.174 & 1.49 \\
\hline
\end{tabular}


emphysematous subjects are presented. The effciency of the respiratory muscles of the normal subjects ranged between 7.20 and 11.10 per cent (mean, 8.58 per cent) while the efficiency of the emphysematous subjects was considerably less, ranging between 1.24 and 2.74 per cent (mean, 1.83 per cent).

Also shown in Table III are calculations of total mechanical work of breathing at rest. It can be seen that the total mechanical work of breathing tended to be less in patients with pulmonary emphysema than in the normal subjects, whether expressed as work per liter of ventilation or work per minute.

\section{DISCUSSION}

The data presented indicate that the use of a "closed-circuit" technique yields values for oxygen cost of breathing and efficiency of the respiratory muscles which are comparable to those obtained by the "open-circuit" technique.

It is recognized that values obtained for oxygen consumption or efficiency of the respiratory muscles for handling added work loads will depend upon the resistance offered by the apparatus used. The values reported in this paper, therefore, are not absolute but do serve to distinguish distinctly between normal and emphysematous subjects.

The values for the oxygen consumption of the respiratory muscles in the normal individuals studied are similar to those reported by previous investigators (1-4) but those for efficiency are slightly higher than previously supposed (1).

The results reported in this study indicate that in the emphysematous subjects the oxygen consumption of the respiratory muscles is considerably higher than in the normals. In addition, small increases in ventilation are associated with marked increases in oxygen consumption in the emphysematous patient. These findings are comparable to those previously reported $(2,4)$. The efficiency of the respiratory muscles in the emphysematous subjects is considerably lower than in the normals. This is in disagreement with the findings of Fritts and Cournand (5) but it must be pointed out that they measured work done on the lungs only.

Although total mechanical work has been measured while the subject was ventilated in a respirator
$(6,7)$, there is at present no method available for measuring the total mechanical work of breathing during spontaneous respiration. The method described in this paper may yield an indirect measurement. The values for total work found in normal individuals are considerably higher than has previously been supposed (6). However, previous measurements of total work were no greater than that of work done on the lungs alone $(8,9)$ and were probably, therefore, an underestimation.

The data obtained suggest that the total mechanical work performed on lung and thorax tends to be less in the emphysematous than in normal individuals at low ventilations. This might be expected since about 63 per cent of the work of breathing is performed in overcoming elastic resistances (6) and a substantial loss of lung elasticity occurs in emphysema (8).

Though the total mechanical work done on lungs and thorax tends to be less at low ventilations in patients with emphysema than in normals, the oxygen cost of breathing is four to five times greater because of the markedly reduced efficiency of the respiratory muscles. With increases in ventilation there is a disproportionate increase in oxygen consumption of the respiratory muscles in emphysema. This may help to explain the disability present in pulmonary emphysema and the inability of the severely emphysematous patient to meet the increased energy demands of exercise and infection.

\section{SUMMARY AND CONCLUSIONS}

1. The oxygen consumption of the respiratory muscles was measured in 16 normal and 22 emphysematous subjects. The oxygen cost of increased ventilation was considerably higher in the emphysematous subjects and rose even further with slight increases in ventilation.

2. The efficiency of the respiratory muscles was determined in nine normal and seven emphysematous subjects. The efficiency was considerably lower than the normal in the patients with emphysema.

3. The total mechanical work at rest, measured indirectly, tended to be less than the normal in the patients with emphysema, whether expressed as work per minute or work per liter of ventilation. 


\section{REFERENCES}

1. Otis, A. B. The work of breathing. Physiol. Rev. 1954, 34, 449.

2. Campbell, E. J. M., Westlake, E. K., and Cherniack, R. M. Simple methods of estimating oxygen consumption and efficiency of the muscles of breathing. J. appl. Physiol. 1957, 11, 303.

3. Liljestrand, G. Untersuchungen über die Atmungsarbeit. Skand. Arch. Physiol. 1918, 35, 199.

4. Cournand, A., Richards, D. W., Jr., Bader, R. A., Bader, M. E., and Fishman, A. P. The oxygen cost of breathing. Trans. Ass. Amer. Phycns 1954, 67, 162.

5. Fritts, H. W., Jr., and Cournand, A. The effect of chronic obstructive emphysema on the efficiency of ventilation during voluntary hyperpnea. 20th Int. Physiol. Congr., Abstracts of Communications, 1956, p. 315.

6. Otis, A. B., Fenn, W. O., and Rahn, H. Mechanics of breathing in man. J. appl. Physiol. 1950, 2, 592.

7. Fishman, A. P., Turino, G. M., and Bergofsky, E. H. The syndrome of alveolar hypoventilation. Amer. J. Med. 1957, 23, 333.

8. Cherniack, R. M. The physical properties of the lung in chronic obstructive pulmonary emphysema. $\mathrm{J}$. clin. Invest. 1956, 35, 394.

9. Mcllroy, M. B., Marshall, R., and Christie, R. V. The work of breathing in normal subjects. Clin. Sci. 1954, 13, 127. 